\title{
Obrada otpadnih tokova nastalih tijekom proizvodnje maslinova ulja
}

\author{
D. Kučić Grgić, D. Krivičić, M. Vuković Domanovac i V. Ocelić Bulatović \\ Sveučilište u Zagrebu, Fakultet kemijskog inženjerstva i tehnologije, Marulićev trg 19, 10000 Zagreb
}

Ovo djelo je dano na korištenje pod Creative Commons Attribution 4.0

\begin{abstract}
Sažetak postignuta je konverzija od $45 \%$.

Ključne riječi

Otpadna voda, komina maslina, adsorpcija, biosorpcija, kompostiranje
\end{abstract}

Otpadni tokovi nastali tijekom proizvodnje maslinova ulja karakterizirani su niskom pH, visokom električnom vodljivošću, tamnom bojom, visokim udjelom fenola, šećera i organskih kiselina. U ovom radu prikazani su rezultati uklanjanja onečišćujućih tvari iz otpadne vode procesom adsorpcije i biosorpcije na aktivni ugljik i pelete Aspergillus niger te zbrinjavanje komine maslina procesom kompostiranja. Dobiveni rezultati pokazuju da je aktivni ugljik adsorbirao $35 \%$ organske tvari i $47 \%$ fenola, a peleti $42 \%$ organske tvari, $57 \%$ fenola i $39 \%$ boje. Tijekom procesa kompostiranja komine maslina i duhanskog otpada

\section{Uvod}

Narušavanje prirodne ravnoteže i uništavanje pojedinih ekosustava posljedica je ljudske aktivnosti vezane uz industriju, intenzivnu poljoprivredu, graditeljstvo, promet itd. Ishod navedenih djelatnosti dovodi do onečišćenja tla, podzemnih i površinskih voda, mora, zraka, uništavanja šuma, promjene klime, smanjivanja ozonskog sloja u atmosferi te smanjivanja biološke raznolikosti. ${ }^{1}$ Kako bi se negativni utjecaji na okoliš sveli na najmanju moguću mjeru, otpadnim tokovima je potrebno gospodariti na odgovarajući način poštujući hijerarhiju gospodarenja otpadom, odnosno obraditi otpad tako da se iz njega izdvoje korisne sirovine od kojih će nastati novi proizvod ili će imati neku drugu upotrebnu vrijednost. ${ }^{2}$

$U$ mediteranskom podneblju široko su rasprostranjeni nasadi maslina te prerada plodova i proizvodnja gotovo najdragocjenijeg proizvoda - maslinova ulja. $U$ agroindustrijskom procesu prerade maslina u svrhu proizvodnje maslinova ulja kao nusprodukti nastaju otpadna voda i komina maslina (slika 1) koje su karakterizirane visokim organskim opterećenjem ${ }^{3}$ i visokom koncentracijom fenola, ${ }^{3}$ niskim $\mathrm{pH},{ }^{4}$ visokom provodnošću, ${ }^{5}$ te su toksične i tamne boje.

Zbog navedenih svojstava otpadna voda i komina maslina se prije odlaganja u okoliš moraju obraditi. Postoje različiti postupci uklanjanja onečišćujućih tvari iz otpadne vode među kojima su fizikalni (adsorpcija, biosorpcija), kemijski (katalitička oksidacija) i biološki (biorazgradnja - kulturama kao što su primjerice Phanerochaete chrysosporium, ${ }^{7}$ Geotrichum candidum ${ }^{8,9}$ ). Ekološki prihvatljivim načinom zbrinjavanja komine maslina smatra se proces kompostiranja. Kompostiranje je proces biorazgradnje supstrata koji u aerobnim uvjetima zajednice mikroorganizama prevode $u$

*Autor za dopisivanje: dr. sc. Dajana Kučić Grgić

e-pošta: dkucic@fkit.hr stabilan produkt-kompost uz oslobađanja plinova (ugljikov dioksid, amonijak), topline i vode. ${ }^{10}$ Proces kompostiranja može se provesti $u$ otvorenom i zatvorenom sustavu, a na sam proces utječu mnogi čimbenici poput omjera $\mathrm{C} / \mathrm{N}$, vlage, $\mathrm{pH}$ i veličine čestica. Prema navedenim čimbenicima koji utječu na proces kompostiranja, komina masline ne može se sama kompostirati, nego ju je potrebno pomiješati s kosupstratom, a u ovom radu kao kosupstrat upotrijebljen je duhanski otpad koji također spada u agroindustrijski otpad i miješanjem s kominom daju zadovoljavajuće početne uvjete.

U ovom radu prikazani su dobiveni rezultati obrade otpadne vode procesom adsorpcije i biosorpcije na aktivni ugljik odnosno na micelijska zrnca Aspergillus niger i zbrinjavanje komine maslina procesom kompostiranja.

\section{Eksperimentalni dio}

\subsection{Materijali}

U ovom radu upotrijebljene su otpadna voda (OVM) i komina masline nastale tijekom procesa proizvodnje maslinova ulja, a porijeklom su iz uljara sjevernog i južnog priobalja Republike Hrvatske. Otpadna voda i komina masline pohranjene su u plastičnim spremnicima u zamrzivaču na temperaturi od $-18{ }^{\circ} \mathrm{C}$. U svrhu podešavanja fizikalno-kemijskih karakteristika supstrata za kompostiranja, komina masline se pomiješala s duhanskim otpadom u omjeru $1: 4$ po suhoj tvari i dodano je $2 \mathrm{dm}^{3}$ vode. Duhanski otpad dopremljen je iz tvornice duhana Rovinj, Hrvatska. Svježi duhanski otpad osušen je na zraku i skladišten u kartonskim kutijama.

Adsorbens i biosorbens koji su se upotrijebili u svrhu obrade otpadne vode su aktivni ugljik (Silcarbon K835, Njemačka) i micelijska zrnca Aspergillus niger (slika 2). Plijesan Aspergillus niger izolirana je iz komine maslina. Veličina 


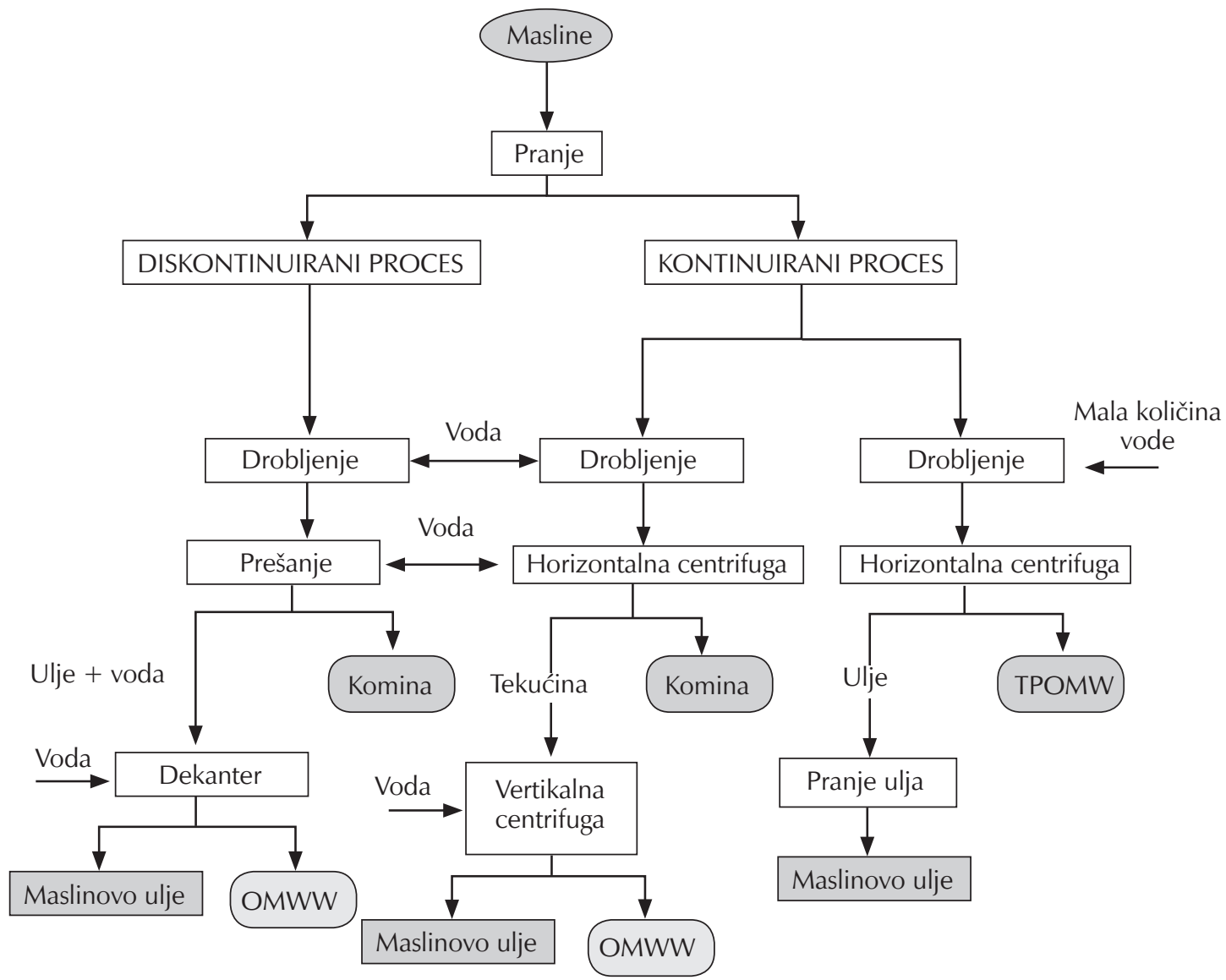

Slika 1 - Osnovni procesi ekstrakcije maslinova ulja ${ }^{6}$

Fig. 1 - Extraction of olive oil ${ }^{6}$

čestica aktivnog ugljika iznosila je 0,6-2,4 mm, a peleta 4- $7 \mathrm{~mm}$. Aktivni ugljik opran je u razrijeđenoj klorovodičnoj kiselini i osušen na $105{ }^{\circ} \mathrm{C}$. Micelijska zrnca Aspergillus niger uzgojila su se u podlozi $\left(V=100 \mathrm{~cm}^{3}\right)$ koja je sadržavala saharozu, $\mathrm{KH}_{2} \mathrm{PO}_{4}, \mathrm{MgSO}_{4} \cdot 7 \mathrm{H}_{2} \mathrm{O}, \mathrm{NH}_{4} \mathrm{NO}_{3}$, $\mathrm{CuSO}_{4} \cdot 5 \mathrm{H}_{2} \mathrm{O}, \mathrm{ZnSO}_{4} \cdot 7 \mathrm{H}_{2} \mathrm{O}$ i $\mathrm{FeCl}_{3} \cdot 6 \mathrm{H}_{2} \mathrm{O} .{ }^{11} \mathrm{U}$ podlogu dodana je prethodno priređena suspenzija spora plijesni $\left(1 \mathrm{~cm}^{3}\right)$, a broj spora iznosio je $2,6 \cdot 10^{6} \mathrm{st} \mathrm{cm}^{-3}$. Erlenmeyerova tikvica postavljena je na termostatiranu rotacijsku tresilicu pri 160 o min $^{-1}$ tijekom $24-48$ sati.

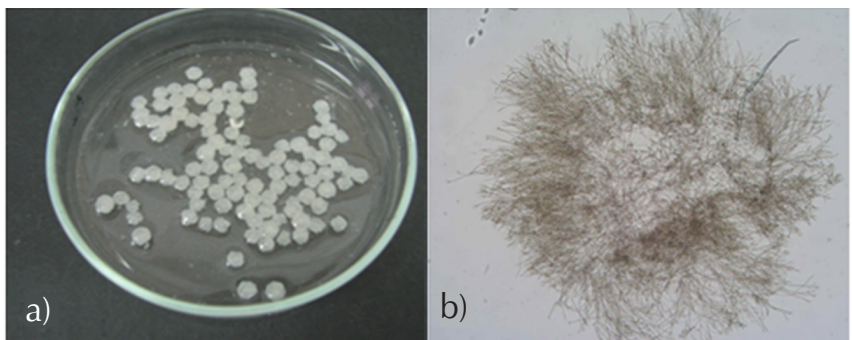

Slika 2 - Uzgojena micelijska zrnca kultura Aspergillus niger (a) i mikrofotografija micelijskog zrna Aspergillus niger pri povećanju od $100 \times(b)$

Fig. 2 - Aspergillus niger fungal pellets (a) and microphotograph of Aspergillus niger fungal pellet magnified 100× (b)

\subsection{Obrada otpadne vode iz procesa proizvodnje maslinova ulja}

$U$ ovom radu provedena je obrada otpadne vode nastale tijekom procesa proizvodnje maslinova ulja postupcima adsorpcije i biosorpcije. Kao adsorbens upotrijebljen je aktivni ugljik, a kao biosorbens uzgojeni peleti Aspergillus niger. Adsorpcija i biosorpcija boje, fenola i organskih tvari iz OVM-a na aktivni ugljik i pelete Aspergillus niger ispitana je u diskontinuiranim uvjetima rada, pokusi P1 i P2, tablica 1.

Tablica 1 - Početne vrijednosti i radni uvjeti za pokuse P1 i P2

Table 1 - Initial values and working conditions for experiments $\mathrm{P} 1$ and P2

\begin{tabular}{|c|c|}
\hline $\begin{array}{l}\text { Fizikalno-kemijski pokazatelji } \\
\text { Physicochemical and microbiological indicators }\end{array}$ & $\begin{array}{l}\text { Vrijednost } \\
\text { Value }\end{array}$ \\
\hline $\mathrm{pH},-$ & 5,50 \\
\hline$\lambda, \mathrm{mS} \mathrm{cm}^{-1}$ & 2,79 \\
\hline$\gamma\left(\right.$ vrijednost KPK), mg dm ${ }^{-3}$ & $7.977,00$ \\
\hline$\gamma($ fenola $), \mathrm{mg} \mathrm{dm}^{-3}$ & 57,00 \\
\hline boja, - & 1,45 \\
\hline$V\left(\right.$ otpadne vode), $\mathrm{cm}^{3}$ & 50 \\
\hline$m$ (adsorbensa $_{\text {suhe tvari, }} \mathrm{g}$ & 0,5 \\
\hline 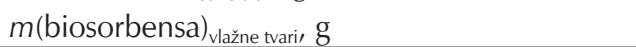 & 0,5 \\
\hline
\end{tabular}


Masa adsorbensa iznosila je 0,5 g, volumen otpadne vode $50 \mathrm{~cm}^{3}$, a odabrani su na temelju prijašnjih provedenih eksperimenata. Pokusi P1 i P2 provedeni su na termostatiranoj rotacijskoj tresilici pri $25{ }^{\circ} \mathrm{C}$ i brzini okretaja

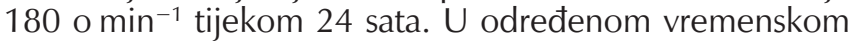
intervalu iz tikvica su izuzimani određeni alikvoti, filtrirani kroz membranski filtar Sartorious (pore 0,45 $\mu \mathrm{m}$ ) te su spektrofotometrijski ${ }^{12}$ praćene koncentracije boje, fenola te vrijednosti KPK.

\subsection{Obrada komine maslina procesom kompostiranja}

Kompostiranje lignoceluloznog materijala provedeno je $\mathrm{u}$ adijabatskom reaktoru radnog volumena $10 \mathrm{dm}^{3}$ tijekom 28 dana (slika 3). Zrak je upuhivan na dnu reaktora, a protok ulaznog zraka podešen je rotametrom. Izlaz iz rotametra spojen je na bocu ispiralicu postavljenu prije reaktora. Na izlazu iz reaktora sakupljan je kondenzat, a izlazni plinovi, $\mathrm{CO}_{2}$ i $\mathrm{NH}_{3}$, apsorbirani su u $1 \mathrm{~mol} \mathrm{dm}^{-3}$ $\mathrm{NaOH}$ odnosno $4 \% \mathrm{H}_{3} \mathrm{BO}_{3} .{ }^{13}$ Temperaturna osjetila smještena su na ulazu i u sredini reaktora te spojena na osobno računalo, a primjenom programa Lab View očitavala se temperatura. Uzorkovanje se provodilo kroz otvor na vrhu reaktora.

U tablici 2 dani su početni radni uvjeti procesa kompostiranja, pokus P3. Tijekom procesa kompostiranja u uzorku supstrata određivani su: udio vlage, ${ }^{14}$ suha tvar, ${ }^{14}$ hlapljiva tvar, ${ }^{14} \mathrm{pH},{ }^{14}$ temperatura, omjer $\mathrm{C} / \mathrm{N}^{14}$ i ukupan broj mezofilnih i termofilnih mikroorganizama. ${ }^{15}$

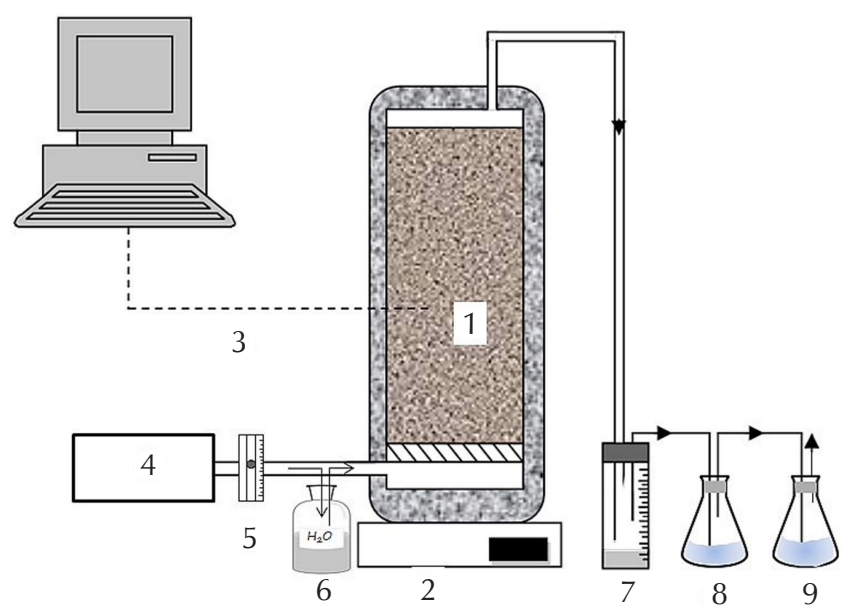

Slika 3 - Shematski prikaz procesa kompostiranja: 1 - reaktor, 2 - vaga, 3 - temperaturna osjetila s akvizicijom, 4 kompresor, 5 - rotametar, 6 - boca ispiralica, 7 - posuda za prikupljanje kondenzata, $8-4 \% \mathrm{H}_{3} \mathrm{BO}_{3}, 9-$ $1 \mathrm{moldm}^{-3} \mathrm{NaOH}$

Fig. 3 - Schematic diagram of the composting process: 1 - reactor, 2 - scale, 3 - temperature data acquisition system, 4 - compressor, 5 - flowmeter, 6 - Drechsel bottle, 7 - graduated cylinder, 8-4\% $\mathrm{H}_{3} \mathrm{BO}_{3}, 9-1 \mathrm{~mol} \mathrm{dm}^{-3}$ $\mathrm{NaOH}$
Tablica 2 - Početni uvjeti procesa kompostiranja za pokus P3

Table 2 - Initial working conditions for composting process in experiment $\mathrm{P} 3$

\begin{tabular}{|c|c|}
\hline $\begin{array}{c}\text { Početni uvjeti } \\
\text { Initial working conditions }\end{array}$ & P3 \\
\hline$V($ reaktor $), \mathrm{dm}^{3}$ & 10,00 \\
\hline$m_{\text {vlažne tvari, }}, \mathrm{kg}$ & 4,50 \\
\hline$w_{0}\left(\mathrm{H}_{2} \mathrm{O}\right), \%$ & 62,00 \\
\hline$w_{0}$ (hlapljive tvari), \% & 80,01 \\
\hline Qz, $\mathrm{dm}^{3} \mathrm{~min}^{-1} \mathrm{~kg}_{\mathrm{HT} 0}{ }^{-1}$ & 0,84 \\
\hline omjer C/N, - & $25: 1$ \\
\hline
\end{tabular}

\section{Rezultati i rasprava}

\subsection{Obrada otpadne vode iz procesa proizvodnje maslinova ulja}

U tablici 3 dani su rezultati fizikalno-kemijske i mikrobiološke karakterizacije otpadne vode iz proizvodnje maslinova ulja. Prema literaturi ${ }^{3-5,16-18}$ te iz tablice 3 može se vidjeti da otpadnu vodu iz proizvodnje maslinova ulja (OVM) karakterizira niski pH, visoka električna vodljivost, visoka koncentracija suspendiranih tvari, vrijednosti KPK i fenola. Svi ti pokazatelji ukazuju da je OVM izrazito opterećena organskom tvari i da se kao takva ne smije ispustiti u okoliš. Mikrobiološkom analizom utvrđen je ukupni broj

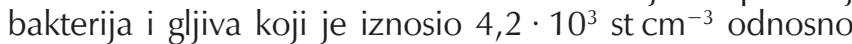
$1,9 \cdot 10^{7} \mathrm{st} \mathrm{cm}^{-3}$, od toga je $1,56 \cdot 10^{7} \mathrm{st} \mathrm{cm}^{-3}$ kvasaca, a

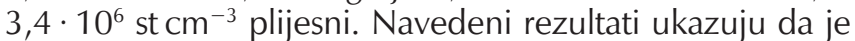
OVM dobar medij za rast gljiva, odnosno plijesni i kvasca, zbog niskog pH OVM-a (tablica 3).9,19

U ovom radu provedeno je uklanjanje onečišćujućih tvari iz OVM-a procesom adsorpcije i biosorpcije na aktivni ugljik i micelijska zrnca Aspergillus niger. Početni uvjeti procesa dani su u tablici 1. Početna vrijednost KPK iznosila je $8000 \mathrm{mg} \mathrm{dm}^{-3}$, a koncentracija fenola $57 \mathrm{mg} \mathrm{dm}^{-3}$. Iz slike 4 može se vidjeti kako se tijekom prvih 120 minuta pokusa vrijednost KPK, fenola i boje smanjila za $35 \%$, $47 \%$ odnosno $0 \%$ upotrebom aktivnog ugljika, a upotrebom peleta Aspergillus niger za 42 \%, 57 \% i 39 \%. Prema navedenim rezultatima može se zaključiti da se nakon primijenjenog procesa adsorpcije, odnosno biosorpcije OVM mora podvrgnuti daljnjoj obradi jer su izlazne vrijednosti pokazatelja iznad propisanih vrijednosti prema Pravilniku O graničnim vrijednostima emisija otpadnih voda. ${ }^{20}$ Prema Pravilniku dopuštena koncentracija ukupnog organskog opterećenja izraženog preko vrijednosti KPK i fenola u otpadnim vodama ne smije biti veća od $700 \mathrm{mg} \mathrm{dm}^{-3}$, odnosno $10 \mathrm{mg} \mathrm{dm}^{-3}$ za ispust u sustav javne odvodnje. Jedan od mogućih načina obrade OVM-a nakon fizikalno-kemijske obrade je biološka obrada aktivnim muljem, ${ }^{21}$ odnosno različitim vrstama mikroorganizama. ${ }^{7-9}$ 
Tablica 3 - Fizikalno-kemijska i mikrobiološka karakterizacija otpadne vode koja nastaje tijekom procesa proizvodnje maslinova ulja

Table 3 - Physicochemical and microbial characterization of olive mill wastewater arising from production of olive oil

\begin{tabular}{l|c}
\hline $\begin{array}{l}\text { Fizikalno-kemijski i mikrobiološki pokazatelji } \\
\text { otpadne vode }\end{array}$ & $\begin{array}{c}\text { Vrijednost } \\
\text { Physicochemical and microbiological } \\
\text { indicators of wastewater }\end{array}$ \\
\hline $\mathrm{pH},-$ & 4,94 \\
$\lambda, \mathrm{mS} \mathrm{cm}^{-1}$ & 11,54 \\
$\gamma\left(\right.$ vrijednost KPK), $\mathrm{mg} \mathrm{dm}^{-3}$ & $62.640,00$ \\
$\gamma($ fenola), mg dm & \\
$\gamma\left(\right.$ suspendirane tvari), $\mathrm{mg} \mathrm{dm}^{-3}$ & 370,00 \\
mezofilne bakterije CFU, st cm & \\
mezofilne gljive CFU, st cm &
\end{tabular}

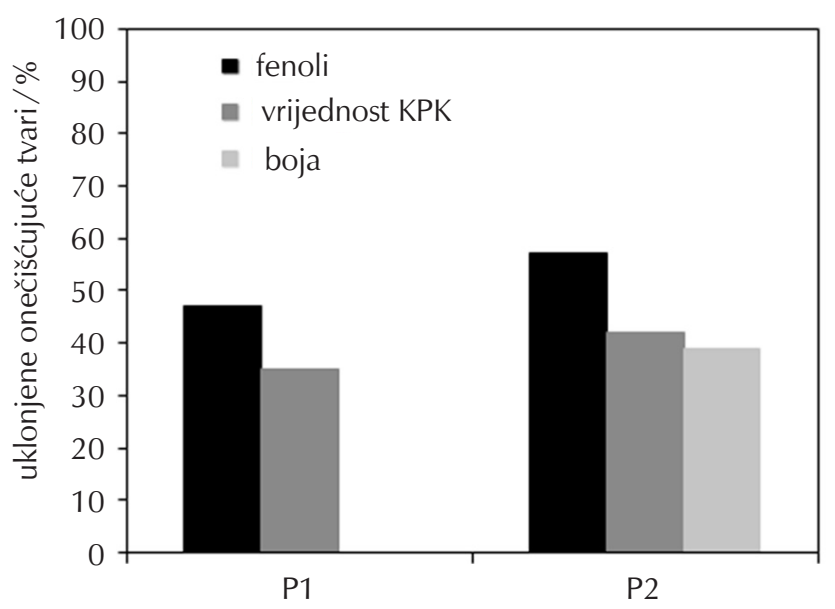

Slika 4 - Postotak uklonjene boje, fenola i ukupnog organskog opterećenja izraženog preko vrijednosti KPK u pokusima P1 (adsorbens - aktivni ugljik) i P2 (biosorbens - peleti Aspergillus niger) nakon $120 \mathrm{~min}(\mathrm{~m}=0,5 \mathrm{~g}$, $V=50 \mathrm{~cm}^{3}, T=25^{\circ} \mathrm{C}$ i $180 \mathrm{o} \mathrm{min}^{-1}$ )

Fig. 4 - Removal percentage of colour, phenols and COD values in experiment P1 (adsorbent - activated carbon) and P2 (biosorbent - Aspergillus niger pellets) after $120 \mathrm{~min}$ $\left(m=0,5 \mathrm{~g}, V=50 \mathrm{~cm}^{3}, T=25^{\circ} \mathrm{C}\right.$, and $\left.180 \mathrm{rpm}\right)$

\subsection{Obrada komine maslina procesom kompostiranja}

Prije samog postavljanja pokusa kompostiranja komine maslina i duhanskog otpada provedena je fizikalno-kemijska i mikrobiološka karakterizacija navedenih supstrata. $\mathrm{U}$ tablici 4 navedene su dobivene vrijednosti za kominu maslina te se uočava kako je udio hlapljive tvari veći od $97 \%$, dok je pH niži u odnosu na duhanski otpad. Prema literaturi, 22,23 osim navedenog, kominu karakterizira visok omjer $\mathrm{C}: \mathrm{N}$, visoka koncentracija suspendiranih tvari koja prelazi i $90 \%$, vrijednosti KPK veće od $190 \mathrm{~g} \mathrm{O}_{2} \mathrm{dm}^{-3}$ i koncentracije fenola koje prema nekim istraživanjima prelaze $106 \mathrm{mg} \mathrm{g}_{\text {suhe tvari }}{ }^{-1}$. Prema literaturi ${ }^{24-27} \mathrm{i}$ iz tablice 4 može se vidjeti da duhanski otpad u odnosu na kominu masline karakterizira niži udio organske tvari, viši pH, ni- zak udio vlage i nizak omjer C : N. Prema ukupnom broju mezofilnih i termofilnih bakterija i gljiva može se vidjeti da su oba supstrata dobar medij za rast mikroorganizama. S obzirom na početne fizikalno-kemijske i mikrobiološke karakteristike može se vidjeti da se miješanjem navedenih supstrata mogu postići optimalni početni uvjeti potrebni za provedbu procesa kompostiranja. Duhanski otpad izabran je kao kosupstrat za kompostiranje ne samo zbog fizikalno-kemijskih značajki nego zbog toga što oba supstrata spadaju u agroindustrijski otpad i potječu iz istog područja, sjevernog Jadrana.

Na slici 5 prikazana je promjena temperature kompostne mase i promjene masenog udjela ugljikova dioksida na izlazu iz reaktora tijekom 28 dana procesa. Na početku procesa temperatura kompostne mase iznosila je $24{ }^{\circ} \mathrm{C}$ te je nakon 24 sata porasla na $30^{\circ} \mathrm{C}$. Naredna 24 sata bilježio se eksponencijalni rast kada započinje termofilna faza te je temperatura kompostne mase bila oko $50{ }^{\circ} \mathrm{C}$. Od četvrtog do dvanaestog dana bilježio se blagi pad te izmjerena temperatura u 12 danu iznosila je $39^{\circ} \mathrm{C}$ nakon čega je do petnaestog dana ponovno rasla i dosegnula temperaturu od $45{ }^{\circ} \mathrm{C}$. Nakon 16 dana temperatura se smanjivala sve do kraja procesa kompostiranja. Aktivnost pojedinih vrsta mikroorganizma uzrokuje razgradnju organskih frakcija i promjenu temperature. ${ }^{2}$ Porast temperature izravno je povezan s izraženijom biokemijskom aktivnosti termofilnih zajednica mikroorganizama, što potvrđuje i porast masenog udjela $\mathrm{CO}_{2}$ na izlazu iz reaktora, nakon čega $\mathrm{u}$ fazi hlađenja ponovno dolazi do aktivacije mezofilnih mikroorganizama. ${ }^{28,29}$ Tijekom prvih dvadeset dana procesa, razgradnja organske tvari je najintenzivnija te je u tom razdoblju detektirano najviše $\mathrm{CO}_{2}$ u izlaznoj struji zraka. Nakon dvadesetog dana udio $\mathrm{CO}_{2}$ se smanjuje, što se izravno može povezati sa smanjenom aktivnošću mikroorganizama. ${ }^{30}$ Tijekom 28 dana procesa kompostiranja nastalo je ukupno $123 \mathrm{~g} \mathrm{~kg}_{\mathrm{HTO}}^{-1} \mathrm{CO}_{2}$ (tablica 5).

U tablici 5 prikazani su dobiveni rezultati procesom kompostiranja. Može se vidjeti kako je u 28 dana postignuta konverzija od $45 \%$ te da se omjer C/N smanjio od 25/1 do 14/1. Nadalje, pH supstrata je na početku iznosio 6,45, a na kraju pokusa 8,29 , što ukazuje na amonifikaciju supstrata. ${ }^{31}$ Praćenjem koncentracije $\mathrm{NH}_{3}$ na izlazu iz reaktora tijekom 28 dana procesa kompostiranja, amonijak se detektirao u tragovima u 20. danu kada je i pH supstrata bio iznad 8. Prema rezultatu u tablici 5 može se vidjeti da je $\mathrm{NH}_{3}$ nastalo tek oko $8 \mathrm{mg} \mathrm{kg}^{-1}$. Prema objavljenim rezultatima $^{32}$ kompostiranjem samog duhana i mješavine duhana i grožđa nastalo je $504,81 \mathrm{mg} \mathrm{kg}^{-1}$ odnosno $122,46 \mathrm{mg} \mathrm{kg}^{-1}$ $\mathrm{NH}_{3}$ u izlaznoj struji plinova, što je znatno više u odnosu na kompostiranje mješavine duhana i komine maslina. $\mathrm{Na}$ temelju dobivenih rezultata vidi se da se komina masline uspješno razgradila procesom kompostiranja uz dodatak duhanskog otpada kao kosupstrata. S obzirom na to da je komina masline sezonski otpad i činjenice da se u primorskom dijelu velik dio stanovništva bavi uzgojem maslina, bilo bi poželjno kompostirati mješavinu komine maslina s biootpadom i zelenim otpadom koji su stanovništvu dostupni s obzirom na to da duhan nije. Također, dobiveni kompost trebalo bi dati na analizu da se utvrdi može li se odložiti na tlo, odnosno da ne sadrži teške metale, pesticide i ostale zakonom propisane tvari. ${ }^{33}$ 
Tablica 4 - Fizikalno-kemijska i mikrobiološka karakterizacija komine maslina, duhana i mješavine duhana i komine maslina za kompostiranje

Table 4 - Physicochemical and microbiological characterization of the initial olive mill waste, tobacco waste and mixture of tobacco and olive mill waste

\begin{tabular}{|c|c|c|c|}
\hline $\begin{array}{l}\text { Fizikalno-kemijski i mikrobiološki } \\
\text { pokazatelji } \\
\text { Physicochemical and microbiological } \\
\text { indicators }\end{array}$ & $\begin{array}{l}\text { Komina masline } \\
\text { Initial olive mill waste }\end{array}$ & $\begin{array}{l}\text { Duhanski otpad } \\
\text { Tobacco waste }\end{array}$ & $\begin{array}{c}\text { Mješavina duhanskog otpada i } \\
\text { komine maslina } \\
\begin{array}{c}\text { Mixture of tobacco and olive } \\
\text { mill waste }\end{array}\end{array}$ \\
\hline $\mathrm{pH},-$ & 5,55 & 7,10 & 6,45 \\
\hline$w\left(\mathrm{H}_{2} \mathrm{O}\right), \%$ & 57,80 & 19,90 & 61,90 \\
\hline$w($ suhe tvari) $\%$ & 42,20 & 80,10 & 38,10 \\
\hline$w$ (hlapljive tvari), \% & 97,30 & 80,10 & 82,70 \\
\hline omjer $\mathrm{C}: \mathrm{N},-$ & $45: 1$ & $16: 1$ & $25: 1$ \\
\hline mezofilne bakterije CFU, st g suhe tvari $^{-1}$ & $3,00 \cdot 10^{8}$ & $4,09 \cdot 10^{9}$ & $1,00 \cdot 10^{10}$ \\
\hline termofilne bakterije CFU, st gsuhe tvari ${ }^{-1}$ & $3,90 \cdot 10^{6}$ & $1,84 \cdot 10^{9}$ & $5,42 \cdot 10^{10}$ \\
\hline mezofilne gljive CFU, stg $_{\text {suhe tvari }}{ }^{-1}$ & - & $1,23 \cdot 10^{7}$ & $5,15 \cdot 10^{9}$ \\
\hline termofilne gljive $\mathrm{CFU}$, stg $_{\text {suhe tvari }}{ }^{-1}$ & - & $5,23 \cdot 10^{7}$ & $5,54 \cdot 10^{8}$ \\
\hline
\end{tabular}

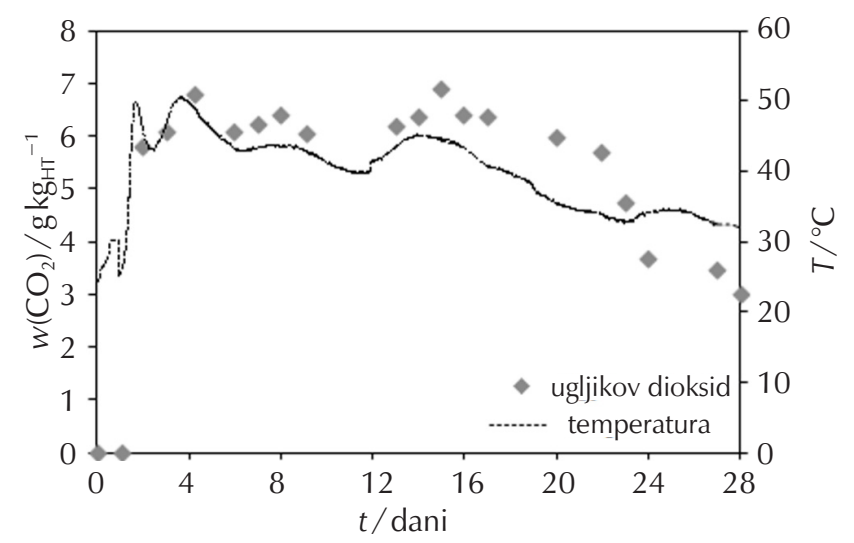

Slika 5 - Promjena masenog udjela $\mathrm{CO}_{2}$ u struji zraka na izlazu iz reaktora i temperature tijekom 28 dana procesa kompostiranja u pokusu P3

Fig. 5 - Change in temperature and $\mathrm{CO}_{2}$ during 28 days of experiment $\mathrm{P} 3$

Tablica 5 - Rezultati procesa kompostiranja (P3)

Table 5 - Results of composting process (P3)

\begin{tabular}{l|c|c}
\hline $\begin{array}{l}\text { Fizikalno-kemijski } \\
\text { pokazatelji } \\
\text { Physicochemical indicators }\end{array}$ & $\begin{array}{c}\text { Početak pokusa } \\
\text { (0. dan) } \\
\text { Experiment start } \\
\text { (day 0) }\end{array}$ & $\begin{array}{c}\text { Kraj pokusa } \\
\text { (28. dan) } \\
\text { Experiment end } \\
\text { (day 28) }\end{array}$ \\
\hline omjer C/N, - & $25 / 1$ & $14 / 1$ \\
$X, \%$ & 0 & 45,00 \\
$\mathrm{pH}_{\text {supstrata, }}-$ & 6,45 & 8,29 \\
$m_{\text {vlažne tvari, }}, \mathrm{kg}^{3}$ & 4,5 & 3,60 \\
$V_{\text {kondenzata' }}$ & 0 & 290,00 \\
$w\left(\mathrm{CO}_{2}\right), \mathrm{g} \mathrm{kg}_{\mathrm{HT}}{ }^{-1}$ & 0 & 123,00 \\
$w\left(\mathrm{NH}_{3}\right), \mathrm{mg} \mathrm{kg}^{-1}$ & 0 & 7,75 \\
\hline
\end{tabular}

\section{Zaključak}

Otpadni tokovi (otpadna voda i komina maslina) nastali tijekom proizvodnje maslinova ulja jako su opterećeni organskim tvarima, fenolima, imaju niski $\mathrm{pH}$ i visoku vodljivost, te se kao takvi ne smiju ispustiti u okoliš bez prethodne obrade. Na temelju provedenih pokusa, P1 i P2, može se zaključiti da je uklonjeno 35 \% ukupne organske tvari izražene kao vrijednost KPK i 47 \% fenola procesom adsorpcije na aktivni ugljik, odnosno 42 \% i 57 \% procesom biosorpcije na pelete Aspergillus niger. Procesom biosorpcije uklonjeno je 39 \% boje. Navedenim postupcima uklonile su se onečišćujuće tvari iz otpadne vode, međutim koncentracije KPK-a i fenola i dalje su iznad dopuštenih, te je otpadnu vodu potrebno dalje obraditi. Uz otpadnu vodu kao nusprodukt proizvodnje maslinova ulja nastaje i komina maslina, a jedan od načina zbrinjavanja je proces kompostiranja. S obzirom na njezine početne fizikalno-kemijske karakteristike komina se ne može sama kompostirati, nego je potrebno dodati kosupstrat, u ovom slučaju duhan, koji će zajedno u kombinaciji s kominom dati zadovoljavajuće početne uvjete. Tijekom procesa kompostiranja mješavine duhanskog otpada i komine masline tijekom 28 dana postignuta je 45 \%-tna konverzija, omjer C/N se smanjio s 25/1 na 14/1, nastalo je $290 \mathrm{~cm}^{3}$ kondenzata, $123 \mathrm{~g} \mathrm{~kg}_{\mathrm{HT} 0}{ }^{-1} \mathrm{CO}_{2}$ i $8 \mathrm{mg} \mathrm{kg}^{-1} \mathrm{NH}_{3}$. Tijekom procesa kompostiranja izmjenjivale su se tri faze: mezofilna, termofilna i faza hlađenja, odnosno druga mezofilna faza. Na temelju dobivenih rezultata može se zaključiti da su primijenjeni načini obrade učinkovito uklonili odnosno razgradili onečišćujuće tvari iz vode i komine, a kao jedna od mogućnosti koju bi bilo poželjno ispitati je kompostiranje mješavine komine s biootpadom koji je ljudima svakodnevno dostupan s ciljem dobivanja gnojiva za oplemenjivanje tla, a otpadnu vodu upotrijebiti za podešavanje vlažnosti. 


\section{Popis kratica i simbola List of abbreviations and symbols}

\begin{tabular}{|c|c|}
\hline CFU & $\begin{array}{l}\text { - ukupan broj živih stanica } \\
\text { - colony forming units }\end{array}$ \\
\hline HT & $\begin{array}{l}\text { - hlapljiva tvar } \\
\text { - volatile matter }\end{array}$ \\
\hline $\begin{array}{l}\text { KPK } \\
\text { COD) }\end{array}$ & $\begin{array}{l}\text { - kemijska potrošnja kisika } \\
\text { - chemical oxygen demand }\end{array}$ \\
\hline VM & $\begin{array}{l}\text { - otpadna voda iz proizvodnje maslinova ulja } \\
\text { - olive mill wastewater }\end{array}$ \\
\hline & $\begin{array}{l}\text { - masa, kg } \\
\text { - mass, kg }\end{array}$ \\
\hline & $\begin{array}{l}\text { - vrijeme, dani } \\
\text { - time, days }\end{array}$ \\
\hline$T$ & $\begin{array}{l}\text { - temperatura, }{ }^{\circ} \mathrm{C} \\
\text { - temperature, }{ }^{\circ} \mathrm{C}\end{array}$ \\
\hline$W$ & $\begin{array}{l}\text { - maseni udjel, \%, } \mathrm{g} \mathrm{kg}^{-1}, \mathrm{mg} \mathrm{kg}^{-1} \\
\text { - mass fraction, } \%, \mathrm{~g} \mathrm{~kg}^{-1}, \mathrm{mg} \mathrm{kg}^{-1}\end{array}$ \\
\hline & $\begin{array}{l}\text { - konverzija, \% } \\
\text { - conversion, \% }\end{array}$ \\
\hline & $\begin{array}{l}\text { - električna provodnost, } \mathrm{mS} \mathrm{cm}^{-1} \\
\text { - conductivity, } \mathrm{mS} \mathrm{cm}^{-1}\end{array}$ \\
\hline
\end{tabular}

\section{Literatura \\ References}

1. F. Briški, Zaštita okoliša, Element, Zagreb, 2016.

2. L. F. Diaz, M. de Bertoldi, W. Bidlingmaier, (Eds.) Compost Science and technology, Elsevier, Amsterdam, 2007.

3. J. A. Morillo, B. Antizar-Ladislao, M. Monteoliva-Sanchez, A. Ramos-Cormenzana, N. J. Russell, Bioremediation and biovalorisation of olive-mill wastes, Appl Microbiol. Biotechnol. 82 (2009) 25-39, doi: https://doi.org/10.1007/s00253-0081801-y.

4. T. Akar, I. Tosun, Z. Kaynak, E. Ozkara, O. Yeni, E. N. Sahin, S. T. Akar, An attractive agro-industrial by-product in environmental cleanup: Dye biosorption potential of untreated olive pomance, J. Hazard. Mater. 166 (2009) 1217-1225, doi: https://doi.org/10.1016/j.jhazmat.2008.12.029.

5. C. Paredes, J. Cegarra, A. Roig, M. A. Sanchez-Monedero, M. P. Bernal, Characterization of olive-mill wastewater (alpechin) and its sludge for agricultural purposes, Biores. Technol. 67 (1997) 111-115, doi: https://doi.org/10.1016/ S0960-8524(98)00106-0.

6. S. Dermeche, M. Nadour, C. Larroche, F. Moulti-Mati, P. Michaud, Olive mill wastes: Biochemical characterizations and valorization strategies, Process Biochem. 48 (2013) 1532-1552, doi: https://doi.org/10.1016/j. procbio.2013.07.010.

7. J. Mann, J. L. Markham, P. Peiris, N. Nair, R. N. Spooner-Hart, Bioremediation of olive mill wastewater with selected filamentous fungi, $4^{\text {th }}$ BioRemediation Conference, Grčka, 2008.

8. G. Bleve, C. Lezzi, M. A. Chiriatti, I. D'Ostuni, M. Tristezza, D. Di Venere, L. Sergio, G. Mita, F. Grieco, Selection of non-conventional yeasts and their use in immobilized form for the bioremediation of olive oil mill wastewaters, Biores. Technol. 102 (2011) 982-989, doi: https://doi.org/10.1016/j.biortech.2010.09.059.

9. I. G. Garcia, P. R. J. Pena, J. L. B. Venceslada, A. M. Martin, M. A. M Santos, E. R. Gomez, Removal of phenol compounds from olive mill wastewater using Phanerochaete chrysosporium, Aspergillus niger, Aspergillus terreus and Geotrichum candidum, Process. Biochem. 35 (2000) 751-758, doi: https://doi.org/10.1016/S0032-9592(99)00135-1.

10. R. T. Haug, The Practical Handbook of Compost Engineering, Lewis Publisher, USA, 1993.

11. F. Briški, M. Petrović, M. Macan-Kaštelan, L. Sipos, Removal of humic substances from aqueous solution by fungal pellets, Biocatalysis 10 (1994) 1-14, doi: https://doi. org/10.3109/10242429409065213.

12. Standard methods for the examination of waste and wastewater, American public health association, 1999.

13. I. M. Kolthoff, E. B. Sandel, Inorganic quantitative analysis, Zagreb, Croatia: Školska knjiga, (in Croatian), 1951., str. 347-352.

14. Austrian Standards Institute, Austrian standard: Analytical methods and quality control for waste compost, ÖNORM S 2023, Vienna, 1986., Austria.

15. F. Briški, N. Kopčić, I. Ćosić, D. Kučić, M. Vuković, Biodegradation of tobacco waste by composting: Genetic identification of nicotine-degrading bacteria and kinetic analysis of transformations in leachate, Chem. Pap. 66 (2012) 11031110, doi: https://doi.org/10.2478/s11696-012-0234-3.

16. E. S. Aktas, S. Imre, L. Ersoy, Characterization and lime treatment of olive mill wastewater, Water Res. 35 (2001) 2336, doi: https://doi.org/10.1016/S0043-1354(00)00490-5.

17. N. Azbar, A. Bayram, A. Filibeli, A. Muezzinoglu, F. Sengul, A. Ozer, A review of waste management options in olive oil production, Crit. Rev. Env. Sci. Technol. 34 (2004) 209, doi: https://doi.org/10.1080/10643380490279932.

18. H. El Hajjouji, E. Pinelli, M. Guiresse, G. Merlina, J. C. Revel, M. Hafidi, Assessment of the genotoxicity of olive mill waste water $(\mathrm{OMWW})$ with the Vicia faba micronucleus test, Mutat. Res. 634 (2007) 25-31, doi: https://doi.org/10.1016/j. mrgentox.2007.05.015.

19. D. Kučić, Integracija procesa kompostiranja i adsorpcije, Doktorski rad. Zagreb: Fakultet kemijskog inženjerstva i tehnologije. 2010.

20. Pravilnik o graničnim vrijednostima emisija otpadnih voda NN 80/2013.

21. D. Kučić, M. Vuković Domanovac, F. Briški, Kinetics of Aerobic Treatment of two-phase Olive-mill waste by Activated sludge in Sequencing Batch Reactor, The Hol. App. Environ. 7 (2017) 139-155.

22. M. Niaounakis, C. P. Halvadakis, Olive Processing Waste Management: Literature Review and Patent Survey $2^{\text {nd }}$ Ed., Elsevier, Italy, 2006.

23. J. A. Alburquerque, J. Gonzálvez, D. García, J. Cegarra, Agrochemical characterisation of "alperujo", a solid by-product of the two-phase centrifugation method for olive oil extraction, Bioresour. Technol. 91 (2) (2004) 195-200, doi: https:// doi.org/10.1016/S0960-8524(03)00177-9.

24. C. R. Cardoso, M. R. Miranda, K. G. Santos, C. H. Ataíde, Determination of kinetic parameters and analytical pyrolysis of tobacco waste and sorghum bagasse, J. Anal. Appl. Pyrolysis. 92 (2011) 392-400, doi: https://doi.org/10.1016/j. jaap.2011.07.013.

25. G. Tuzzin, M. Godinho, A. Dettmer, A. J. Zattera, Nanofibrillated cellulose from tobacco industry wastes, Carbohydr. Polym. 148 (2016) 69-77, doi: https://doi.org/10.1016/j. carbpol.2016.04.045.

26. S. Agrupis, E. Maekawa, K. Suzuki, Industrial utilization of tobacco stalks II: preparation and characterization of tobacco pulp by steam explosion, J. Wood Sci. 46 (2000) 222-229, doi: https://doi.org/10.1007/BF00776453.

27. N. Okur, H. H. Kayikçioglu, B. Okur, S. Delibacak, Organic Amendment Based on Tobacco Waste Compost and Farm- 
yard Manure: Influence on Soil Biological Properties and Butter-Head Lettuce Yield, Turk. J. Agric. 32 (2008) 91-99.

28. F. Briški, Z. Gomzi, A. Hublin, M. Vuković, Aerobno kompostiranje otpadaka voća i povrća: modeliranje procesa, Kem. Ind. 52 (2003) 95-102.

29. A. Hassen, K. Belguith, N. Jedidi, M. Cherif, A. Boudabous, Microbial characterization during composting of municipal solid waste, Proceedings of International Symposium on Environmental Pollution Control and Waste Management, Tunis, 2002., str. 357-368.

30. J. M. Paillat, P. Robin, M. Hassouna, P. Leterme, Predicting ammonia and carbon dioxide emissions from carbon and nitrogen biodegradability during animal waste composting, Atmos. Environ. 39 (2005) 6833-6842, doi: https://doi. org/10.1016/j.atmosenv.2005.07.045.

31. D. Kučić, N. Kopčić, F. Briški, Zeolite and potting soil sorption of $\mathrm{CO}_{2}$ and $\mathrm{NH}_{3}$ evolved during co-composting of grape and tobacco waste, Chem. Pap. 67 (2013) 1172-1180, doi: https://doi.org/10.2478/s11696-013-0322-z.

32. D. Kučić, F. Briški, Emission of Gases During Composting of Solid Waste, Kem. Ind. 66 (9-10) (2017) 467-474, doi: https://doi.org/10.15255/KUI.2016.050.

33. Zakon o održivom gospodarenju otpadom, NN 94/13.

\section{SUMMARY \\ Treatment of Olive Mill Waste}

Dajana Kučić Grgić, Denija Krivičić, Marija Vuković Domanovac, and Vesna Ocelić Bulatović

The highly loaded olive mill wastes are characterized by low $\mathrm{pH}$ value, high electrical conductivity, and high content of sugar, phenols, and organic acids. In this work are shown the results pollutants removal from olive mill wastewater by adsorption and biosorption process on activated carbon and Aspergillus niger fungal pellets, as well as treatment of olive mill waste by composting process. The obtained results show that activated carbon removed $35 \%$ organic matter and $47 \%$ phenols, while fungal pellets removed $42 \%$ organic matter, $57 \%$ phenols, and $39 \%$ colour. The obtained conversion during composting process of olive mill waste and tobacco was $45 \%$.

\section{Keywords}

Olive mill wastewater, olive mill waste, adsorption, biosorption, composting process

University of Zagreb, Faculty of Chemical Engineering and Technology, Marulićev trg 19, 10000 Zagreb, Croatia
Original scientific paper Received October 31, 2017 Accepted December 5, 2017 